\title{
BMJ Open UK doctors' views on the implementation of the European Working Time Directive as applied to medical practice: a quantitative analysis
}

\author{
Jenny J Maisonneuve, Trevor W Lambert, Michael J Goldacre
}

To cite: Maisonneuve JJ, Lambert TW, Goldacre MJ. UK doctors' views on the implementation of the European Working Time Directive as applied to medical practice: a quantitative analysis. BMJ Open 2014;4: e004391. doi:10.1136/ bmjopen-2013-004391

- Prepublication history for this paper is available online. To view these files please visit the journal online (http://dx.doi.org/10.1136/ bmjopen-2013-004391).

Received 1 November 2013 Revised 13 December 2013 Accepted 10 January 2014

CrossMark

\section{(5) Linked}

- http://dx.doi.org/10.1136/ bmjopen-2013-004390

UK Medical Careers Research Group, Nuffield Department of Population Health, University of Oxford, Old Road Campus, Headington, Oxford, UK

\section{Correspondence to} Trevor W Lambert; trevor.lambert@dph.ox.ac.uk

\section{ABSTRACT}

Objectives: To report on doctors' views, from all specialty backgrounds, about the European Working Time Directive (EWTD) and its impact on the National Health Service (NHS), senior doctors and junior doctors.

Design: All medical school graduates from 1999 to 2000 were surveyed by post and email in 2012.

Setting: The UK.

Methods: Among other questions, in a multipurpose survey on medical careers and career intentions, doctors were asked to respond to three statements about the EWTD on a five-point scale (from strongly agree to strongly disagree): 'The implementation of the EWTD has benefited the NHS', 'The implementation of the EWTD has benefited senior doctors' and 'The implementation of the EWTD has benefited junior doctors'.

Results: The response rate was $54.4 \%$ overall (4486/ 8252), $55.8 \%$ (2256/4042) of the 1999 cohort and $53 \%$ (2230/4210) of the 2000 cohort. $54.1 \%$ (2427) of all respondents were women. Only 12\% (498/4136 doctors) agreed that the EWTD has benefited the NHS, $9 \%(377)$ that it has benefited senior doctors and $31 \%(1289)$ that it has benefited junior doctors. Doctors' views on EWTD differed significantly by specialty groups: 'craft' specialties such as surgery, requiring extensive experience in performing operations, were particularly critical.

Conclusions: These cohorts have experience of working in the NHS before and after the implementation of EWTD. Their lack of support for the EWTD 4 years after its implementation should be a concern. However, it is unclear whether problems rest with the current ceiling on hours worked or with the ways in which EWTD has been implemented.

\section{INTRODUCTION}

The European Working Time Directive (EWTD) mandated the reduction of working hours for doctors in the UK to a maximum of $48 \mathrm{~h}$ /week (averaged over a 6-month period). Its implementation in the National Health

\section{Strengths and limitations of this study}

- This study is a systematic survey of all UK medical graduates from 1999 and 2000 willing to reply. These cohorts have extensive experience of work before and after the full implementation of the European Working Time Directive (EWTD) in medical practice.

- As with all surveys, non-responder bias is possible. The study represents the subjective views of doctors and does not include any objective impact of the EWTD on the National Health Service (NHS), senior or junior doctors.

- Respondents may have had difficulty in separating the effects of EWTD itself, and the way it has been implemented, from those of other reforms to the NHS and medical training.

- We have no information on various factors, such as hospital size or the nature of rotas and the organisation of shift work, that may have influenced doctors' views.

Service (NHS) was phased in over time with partial implementation in $2004(56 \mathrm{~h})$ and full implementation in 2009. In addition to limits on working hours, the EWTD sets out rest periods to limit continuous periods of work. The goal in reducing working hours is to promote doctors' health and safety by decreasing fatigue among doctors, and thereby to improve patient safety. The EWTD has been enshrined in law as the European Working Time Regulations (EWTR) but, for simplicity and using the commoner phrase, we use the term EWTD throughout.

Considerable controversy has surrounded the EWTD in the NHS. Concerns have been raised by bodies such as NHS Employers. ${ }^{1}$ The Royal College of Physicians has expressed concerns that it may have adverse effects on the quality of medical training. ${ }^{2}$ The Royal College of Surgeons has commented on reduced time for training and possible patient safety issues. ${ }^{3}$ An independent review 
was commissioned by Medical Education England (MEE) in 2010 to examine the impact of EWTD on the training of healthcare professionals. ${ }^{4}$ Among other recommendations, the review proposed the implementation of a consultant delivered health service to be 'directly responsible for the delivery of 24/7 care' and to 'work more flexibly to deliver high-quality training and service'.

As part of a multipurpose series of surveys of doctors, mainly aimed at obtaining information about their career intentions, we were struck by the number of spontaneous comments doctors made about EWTD. ${ }^{5}$ In an accompanying paper we reported results of a qualitative analysis of the comments made in 2010 by doctors who qualified in the cohorts of 1993, 2005 and $2010 .{ }^{5}$ The doctors who commented were largely negative about the EWTD. We had not raised EWTD at all in our questionnaires; the doctors wanted to raise it with us. In order to judge whether these were representative views, in our next scheduled surveys in our programme, surveys of the qualifiers of 1999 and 2000, we added a brief section on the EWTD inviting all doctors to express a view. The aim was to get views from all respondents and not just those who self-selected to volunteer their views. The doctors we surveyed had worked for over a decade after qualification, and had experience of working before and after the implementation of the EWTD in the NHS. Our objective in this paper was to report on the views of doctors about whether the implementation of the EWTD had benefited the NHS, senior doctors and junior doctors. We also investigated whether there were differences in views between different specialties and between men and women.

\section{METHODS}

All graduates from all medical schools in the UK in 1999 and 2000 were identified from General Medical Council registrations. We have previously surveyed these doctors $1,3,5$ and 7 years after graduation. ${ }^{6} 7$ In 2012, our fifth survey, over a decade after the doctors' graduation, we included questions about the EWTD.

The questionnaire contained the following three statements: 'The implementation of the EWTD has benefited the NHS', 'The implementation of the EWTD has benefited senior doctors' and 'The implementation of the EWTD has benefited junior doctors'. Doctors were asked to respond to each statement using a five-point scale from 'strongly agree' to 'strongly disagree'. Doctors were also asked a range of questions about their current and previous posts and about their future career intentions. Doctors were sent the questionnaire by post and by email. Several reminders were sent to nonresponders. Further details of our methodology are available elsewhere. ${ }^{8}$

We analysed doctors' responses to the questions overall, by specialty group and gender. Specialties were grouped by us as adult hospital medical specialties, paediatrics, emergency medicine, surgery, obstetrics and gynaecology, anaesthetics, radiology, clinical oncology, pathology, psychiatry, general practice and 'other medical specialties' comprising those in public health and community health. Those unemployed, not working in medicine or with an unknown specialty were not included in the analysis by specialty. We used $\chi^{2}$ tests and adjusted residuals to compare responses by specialty subgroup. Adjusted residuals provide a simple means of identifying specialties in which doctors showed a particularly high or low level of percentage agreement or disagreement with the statements above (also see footnotes to table 1).

\section{RESULTS}

The cohorts of 1999 and 2000 comprised 8652 medical graduates (4219 and 4433, respectively). We excluded from the overall total 279 who were not contactable, 12 deceased and 109 who told us that they did not wish to participate. The response rate was $54.4 \%$ overall (4486/ $8252), 55.8 \%$ (2256/4042) of the 1999 cohort and 53\% (2230/4210) of the 2000 cohort. In total, $54.1 \%$ (2427) of all respondents were women. Of the 4486 replies 290 doctors did not respond to the specific questions concerning the effect of EWTD on senior doctors (154 from 1999 and 136 from 2000) and the NHS (152 from 1999 and 138 from 2000). Two hundred and eighty-one did not respond to the question about junior doctors (152 from 1999 and 129 from 2000). Sixty respondents to the three statements had an unknown specialty, were not working in medicine, or were unemployed.

The implementation of the EWTD has benefited the NHS Overall, $12.0 \%(498 / 4136)$ agreed that the EWTD had benefited the NHS, $58.9 \%$ of doctors $(2436 / 4136)$ disagreed and $29.1 \%(1202 / 4136)$ were neutral. The majority of surgeons $(75.9 \%)$ and of physicians in adult hospital medical specialists $(64.7 \%)$ disagreed, as did $76.5 \%$ of specialists in clinical oncology and $64.6 \%$ of anaesthetists (all four groups had significantly higher levels of disagreement than the all-specialty average, table 1). Psychiatrists (46.6\% disagreement) and general practitioners (GPs; 49.2\%) were significantly less likely to disagree than the all-specialty average (table 1).

\section{The implementation of the EWTD has benefited senior doctors}

Only $9.1 \%$ (377/4136) agreed that the EWTD had benefited senior doctors. The majority disagreed $(63.6 \%$, $2632 / 4136)$ and $27.2 \%(1127 / 4136)$ were neutral. Specialists in clinical oncology $(80.0 \%)$, surgery $(79.3 \%)$ and the adult medical specialties $(69.2 \%)$ had significantly high levels of disagreement, while anaesthetics (68.7\%) and radiology $(68.2 \%)$ also showed high levels of disagreement which did not attain statistical significance (perhaps as a result of smaller numbers). Very few surgeons $(5.7 \%$, 34/593) agreed with the statement. GPs showed a high 
Table 1 Doctors' views, by specialty, on whether the implementation of the European Working Time Directive has benefited the NHS

\begin{tabular}{|c|c|c|c|c|c|c|c|}
\hline \multirow[b]{2}{*}{ Specialty group } & \multicolumn{2}{|c|}{$\begin{array}{l}\text { Strongly agree or } \\
\text { agree }\end{array}$} & \multicolumn{2}{|c|}{$\begin{array}{l}\text { Neither agree nor } \\
\text { disagree }\end{array}$} & \multicolumn{2}{|c|}{$\begin{array}{l}\text { Strongly disagree } \\
\text { or disagree }\end{array}$} & \multirow{2}{*}{$\begin{array}{l}\text { Total } \\
\text { n (100\%) }\end{array}$} \\
\hline & $\mathrm{n}$ & Per cent & $\mathrm{n}$ & Per cent & $\mathrm{n}$ & Per cent & \\
\hline Adult medical specialties & 73 & $9.9^{*}$ & 188 & $25.4^{*}$ & 479 & $64.7^{\star \star}$ & 740 \\
\hline Paediatrics & 36 & $17.8^{\star \star}$ & 57 & 28.2 & 109 & 54.0 & 202 \\
\hline Emergency medicine & 22 & 15.1 & 41 & 28.1 & 83 & 56.8 & 146 \\
\hline Surgery & 47 & $7.9^{\star *}$ & 96 & $16.2^{* *}$ & 451 & $75.9^{\star \star}$ & 594 \\
\hline Obstetrics and gynaecology & 5 & 8.9 & 12 & 21.4 & 39 & 69.6 & 56 \\
\hline Anaesthetics & 50 & 14.5 & 72 & $20.9^{* *}$ & 223 & $64.6^{*}$ & 345 \\
\hline Radiology & 19 & 12.6 & 42 & 27.8 & 90 & 59.6 & 151 \\
\hline Clinical oncology & 3 & $3.7^{\star}$ & 16 & 19.8 & 62 & $76.5^{\star \star}$ & 81 \\
\hline Pathology & 13 & 10.3 & 38 & 30.2 & 75 & 59.5 & 126 \\
\hline Psychiatry & 46 & $19.7^{\star *}$ & 79 & 33.8 & 109 & $46.6^{\star \star}$ & 234 \\
\hline General practice & 176 & 12.5 & 541 & $38.3^{\star \star}$ & 695 & $49.2^{\star \star}$ & 1412 \\
\hline Other medical & 8 & 16.3 & 20 & 40.8 & 21 & 42.9 & 49 \\
\hline$\chi_{11}^{2}, p$ value & 42.6 & $<0.001$ & 133.7 & $<0.001$ & 176.1 & $<0.001$ & \\
\hline Total & 498 & 12.0 & 1202 & 29.1 & 2436 & 58.9 & 4136 \\
\hline
\end{tabular}

The row of $\chi_{11}^{2}$ values and corresponding $p$ values indicates whether the variation in percentages, comparing specialties in each column, can be regarded as random. $p<0.001$ indicates a probability of less than 1 in 1000 that the variation is due to chance.

Asterisks alongside percentages indicate specialties in which doctors take a significantly different view than doctors overall; * denotes $p<0.05$ and ${ }^{* *} p<0.01$, representing respectively a $5 \%$ and a $1 \%$ chance that the specialty variation from the overall average is due to chance.

Sixty respondents whose specialty was unknown, who were unemployed or who did not work in medicine were excluded.

NHS, National Health Service.

level of neutrality, with $36.9 \%$ (520/1410) neither agreeing nor disagreeing with the statement (table 2).

\section{The implementation of the EWTD has benefited junior} doctors

Respondents were more inclined to agree that EWTD had benefited junior doctors in contrast to how they viewed its impact on seniors and on the wider NHS. A total of $31.1 \%(1289 / 4145)$ agreed with the statement, $21.9 \%(912 / 4145)$ were neutral and $46.9 \%(1944 / 4145)$ disagreed. Surgeons (69.9\%), clinical oncologists $(63.0 \%)$ and anaesthetists $(54.8 \%)$ showed higher levels of disagreement than average, while GPs $(38.0 \%)$, psychiatrists $(29.8 \%)$ and specialists in emergency medicine $(37.7 \%)$ had lower than average levels of disagreement (table 3).

\section{Men compared to women}

Women were more inclined than men to express the view that the EWTD had benefited junior doctors (table 4).

Table 2 Doctors' views, by specialty, on whether the implementation of the European Working Time Directive has benefited senior doctors

\begin{tabular}{|c|c|c|c|c|c|c|c|}
\hline \multirow[b]{2}{*}{ Specialty group } & \multicolumn{2}{|c|}{$\begin{array}{l}\text { Strongly agree or } \\
\text { agree }\end{array}$} & \multicolumn{2}{|c|}{$\begin{array}{l}\text { Neither agree nor } \\
\text { disagree }\end{array}$} & \multicolumn{2}{|c|}{$\begin{array}{l}\text { Strongly disagree } \\
\text { or disagree }\end{array}$} & \multirow{2}{*}{$\begin{array}{l}\text { Total } \\
\text { n (100\%) }\end{array}$} \\
\hline & $\mathrm{n}$ & Per cent & $\mathrm{n}$ & Per cent & $\mathrm{n}$ & Per cent & \\
\hline Adult medical specialties & 52 & 7.0 & 177 & $23.8^{*}$ & 514 & $69.2^{\star \star}$ & 743 \\
\hline Paediatrics & 23 & $11.4^{*}$ & 47 & 23.3 & 132 & 65.3 & 202 \\
\hline Emergency medicine & 22 & $15.0^{*}$ & 35 & 23.8 & 90 & 61.2 & 147 \\
\hline Surgery & 34 & $5.7^{\star \star}$ & 89 & $15.0^{\star *}$ & 470 & $79.3^{\star \star}$ & 593 \\
\hline Obstetrics and gynaecology & 5 & 8.9 & 9 & 16.1 & 42 & 75.0 & 56 \\
\hline Anaesthetics & 34 & 9.9 & 74 & $21.4^{*}$ & 237 & $68.7^{*}$ & 345 \\
\hline Radiology & 14 & 9.3 & 34 & 22.5 & 103 & 68.2 & 151 \\
\hline Clinical oncology & 3 & 3.8 & 13 & $16.3^{*}$ & 64 & $80.0^{\star \star}$ & 80 \\
\hline Pathology & 5 & $4.0^{\star}$ & 38 & 30.2 & 83 & 65.9 & 126 \\
\hline Psychiatry & 37 & $15.8^{\star *}$ & 72 & 30.8 & 125 & $53.4^{\star \star}$ & 234 \\
\hline General practice & 142 & 10.1 & 520 & $36.9^{\star *}$ & 748 & $53.0^{\star \star}$ & 1410 \\
\hline Other medical & 6 & 12.2 & 19 & 38.8 & $24^{\star}$ & 49.0 & 49 \\
\hline$\chi_{11}^{2}, p$ value & 41.4 & $<0.001$ & 138.9 & $<0.001$ & 174.3 & $<0.001$ & \\
\hline Total & 377 & 9.1 & 1127 & 27.2 & 2632 & 63.6 & 4136 \\
\hline
\end{tabular}

See notes to table 1 for explanation of statistical terminology $\left(\chi_{11}^{2}, p\right.$ values and asterisks).

Sixty respondents whose specialty was unknown, who were unemployed or who did not work in medicine were excluded. 
Table 3 Doctors' views, by specialty, on whether the implementation of the European Working Time Directive has benefited junior doctors

\begin{tabular}{|c|c|c|c|c|c|c|c|}
\hline \multirow[b]{2}{*}{ Specialty group } & \multicolumn{2}{|c|}{$\begin{array}{l}\text { Strongly agree or } \\
\text { agree }\end{array}$} & \multicolumn{2}{|c|}{$\begin{array}{l}\text { Neither agree nor } \\
\text { disagree }\end{array}$} & \multicolumn{2}{|c|}{$\begin{array}{l}\text { Strongly disagree or } \\
\text { disagree }\end{array}$} & \multirow{2}{*}{$\begin{array}{l}\text { Total } \\
\text { n (100\%) }\end{array}$} \\
\hline & $\mathrm{n}$ & Per cent & $\bar{n}$ & Per cent & $\mathrm{n}$ & Per cent & \\
\hline Adult medical specialties & 219 & 29.4 & 178 & 23.9 & 347 & 46.6 & 744 \\
\hline Paediatrics & 74 & 36.6 & 43 & 21.3 & 85 & 42.1 & 202 \\
\hline Emergency medicine & 62 & $42.5^{\star \star}$ & 29 & $19.9^{*}$ & 55 & $37.7^{\star}$ & 146 \\
\hline Surgery & 109 & $18.4^{\star \star}$ & 70 & $11.8^{\star \star}$ & 415 & $69.9^{\star *}$ & 594 \\
\hline Obstetrics and gynaecology & 18 & 32.1 & 8 & 14.3 & 30 & 53.6 & 56 \\
\hline Anaesthetics & 101 & 29.3 & 55 & $15.9^{\star \star}$ & 189 & $54.8^{\star *}$ & 345 \\
\hline Radiology & 47 & 30.9 & 26 & 17.1 & 79 & 52.0 & 152 \\
\hline Clinical oncology & 15 & $18.5^{\star}$ & 15 & 18.5 & 51 & $63.0^{* *}$ & 81 \\
\hline Pathology & 37 & 29.4 & 21 & 16.7 & 68 & 54.0 & 126 \\
\hline Psychiatry & 110 & $46.8^{\star \star}$ & 55 & 23.4 & 70 & $29.8^{\star *}$ & 235 \\
\hline General practice & 480 & $33.9^{\star \star}$ & 397 & $28.1^{\star \star}$ & 537 & $38.0^{\star \star}$ & 1414 \\
\hline Other medical & 17 & 34.0 & 15 & 30.0 & 18 & 36.0 & 50 \\
\hline$\chi_{11}^{2}, p$ value & 97.0 & $<0.001$ & 84.8 & $<0.001$ & 230.0 & $<0.001$ & \\
\hline Total & 1289 & 31.1 & 912 & 22.0 & 1944 & 46.9 & 4145 \\
\hline
\end{tabular}

See notes to table 1 for explanation of statistical terminology $\left(\chi_{11}^{2}, p\right.$ values and asterisks).

Sixty respondents whose specialty was unknown, who were unemployed or who did not work in medicine were excluded.

Men were more inclined than women to disagree that the implementation of EWTD had benefited the NHS and a higher percentage of women than men held neutral views. Views of men and women about the effect of the EWTD on senior doctors did not differ appreciably.

\section{DISCUSSION}

Main findings

The great majority of doctors did not agree that the EWTD had benefited the NHS or senior doctors.
Doctors were more positive about its benefits for junior doctors but, even so, fewer than a third felt that the EWTD had benefited junior doctors. The negative views of the EWTD 4 years after its implementation indicate that it is a continuing concern for doctors. There were significant differences between respondents in different specialties. Doctors in the surgical specialties, the hospital physician specialties, anaesthetics and clinical oncology were significantly more negative about the implementation of EWTD than the all-specialty average; doctors in psychiatry and general practice were less

Table 4 Doctors' views about the implementation of the European Working Time Directive, comparing the views of men and women

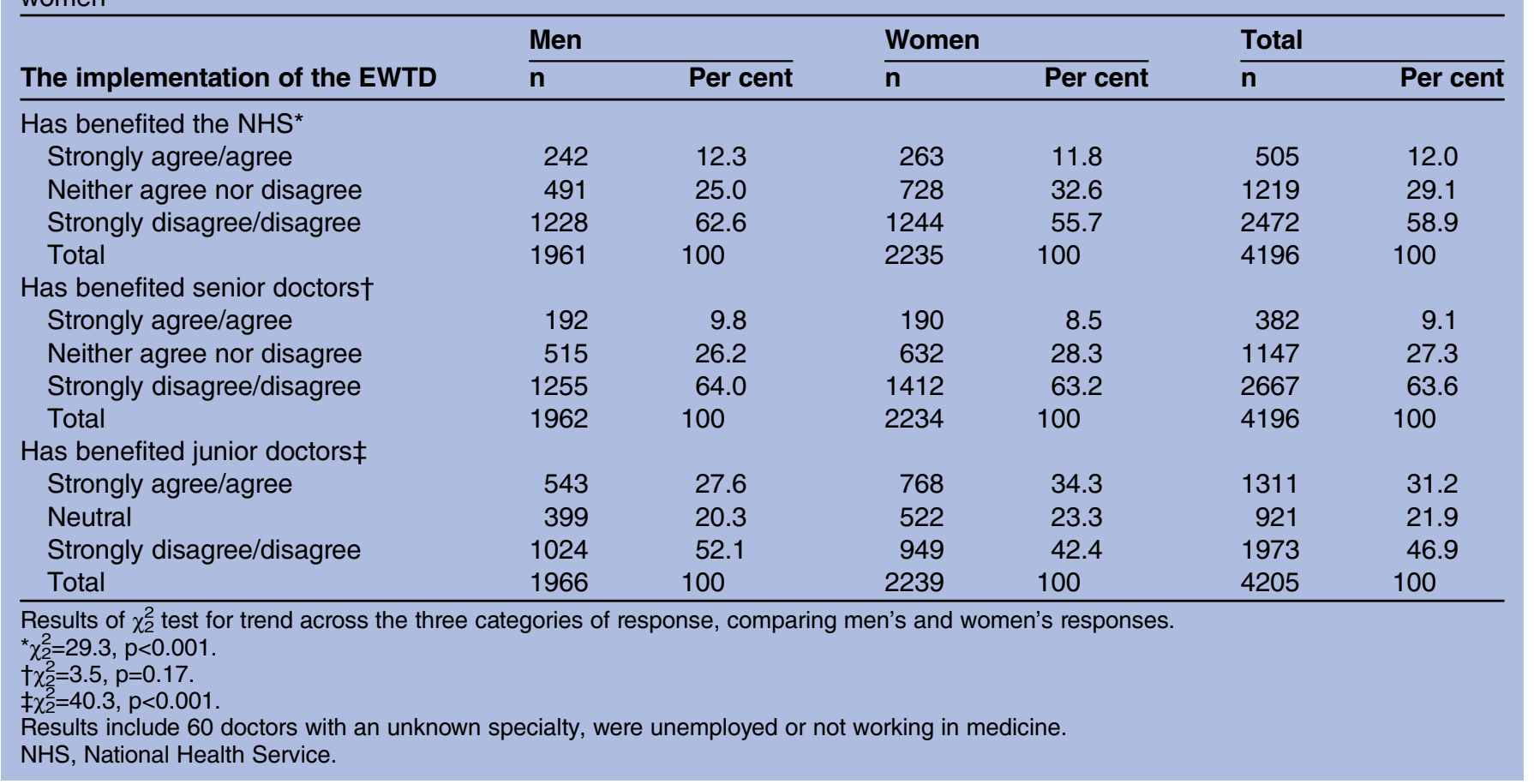


negative. Gender differences in views were modest. Men were, however, rather more negative about the effects of implementing EWTD in respect of the NHS overall and of the effects on junior doctors, than were women, though the views of the effects on senior doctors were equally negative for both genders.

\section{The impact of the EWTD on junior doctors}

The impact of working limits has been studied throughout the 'roll out' of the EWTD. Some studies examined the effect of a $56 \mathrm{~h}$ limit and others of $48 \mathrm{~h}$. The literature concerning perceptions and attitudes towards working time restrictions varies in its quality and generalisability. ${ }^{10}$ Studies of the surgical specialties typically report surgeons to have a negative view of the EWTD. ${ }^{11-}$ 15 Our findings confirm this. Previous studies of the views of surgical trainees have found concerns about reduced contact time with trainers, ${ }^{14}$ reduced clinical exposure and operative experience ${ }^{12} 16$ and adverse impact on patient care. ${ }^{11}{ }^{12}$ Our findings indicate that few surgeons believe junior doctors benefit from the EWTD. The surgical specialties, often regarded as craft specialties, require development of proficient manual dexterity and expertise alongside the development of medical and surgical knowledge. Restricting working hours has been argued to lengthen the amount of time it takes to develop this expertise. ${ }^{17}$ Another issue has been a potential conflict between junior doctors' ability to balance training opportunities with service provision within reduced working hours. ${ }^{18}$ In 2010 the GMC surveyed trainees and asked if they found it was taking longer to achieve educational competencies as a result of $48 \mathrm{~h}$ restrictions from EWTD (with responses invited as yes, unsure and no). They found $51.4 \%$ of surgical trainees, $49.3 \%$ of trainees in obstetrics and gynaecology, and $47.6 \%$ of trainees in anaesthetics believed that it took longer to achieve the required educational competencies. ${ }^{18}$ In contrast, $72.5 \%$ of trainee GPs, $66.3 \%$ in psychiatry, $58.1 \%$ in pathology and $52.7 \%$ in emergency medicine believed that EWTD did not limit the achievement of their educational competencies. ${ }^{18}$

In the context of the EWTD in 2014, it is worth considering the comments we received from doctors whom we studied in similar ways 20 years ago when junior doctors worked very long hours. For example, we studied the qualifiers of 1993 at the end of their pre-registration year in 1994. We reported our concerns about the fact that many trainees wrote telling us of the adverse impact on them of working very long and intensive hours. ${ }^{19}$ As we reported then, ${ }^{19}$ 'some doctors clearly suffered in the preregistration year'. Some made vivid comments about fatigue-related stress. We quoted a doctor who wrote "I have been nearly suicidal throughout some of last year," as a result of exhaustion; and another who wrote "The fact that I haven't killed anyone through exhaustion leading to medical error is a miracle". We reported that a formal keyword search on such terms as 'exhaustion' and 'fatigue' showed that $10 \%$ of all who replied to our questionnaire (259/2621 doctors) in 1994 spontaneously made working-hours-related comments that we considered worrying. Nowadays we get fewer comments like these: in our recent study of the 2012 graduates in 2013, we found only 2 doctors of 2419 respondents mentioned work-related 'exhaustion' or 'fatigue' or 'tiredness', although 'stress' was mentioned by 43 and we get many comments about 'unfairness of unpaid overtime' and not being able to declare non-compliant hours. ${ }^{5}$ To illustrate diversity among doctors ${ }^{19}$ we also quoted one who wrote in the very long working hours of 1994: "I am quite happy with my working hours. Further reductions could be detrimental to the level of experience gained from the job."

Recently, we have shown that doctors in their first year of work, graduating from selected cohorts from 1999 to 2009, have reported increasingly high levels of satisfaction in the recent cohorts, with time off work for leisure and with enjoyment of their work. ${ }^{20}$

\section{The impact of the EWTD on senior doctors}

International research concerning the impact of working time restrictions on senior doctors is limited. Richter $e t a l^{21}$ compared burnout among doctors prior to the implementation of EWTD and post implementation in Hamburg, Germany ( $\mathrm{n}=328)$. While the authors found a decrease in working hours after the implementation of EWTD among junior doctors, a similar decline was not found among seniors. Rather, the results indicated greater strain and burnout among senior physicians with less time for rest. ${ }^{21}$ Hutter $e t a l^{22}$ studied the working hour restriction in the USA to $80 \mathrm{~h} /$ week and found a reduction in burnout among junior but not senior doctors. These results are in line with our findings that the majority of our UK respondents did not believe EWTD benefits senior doctors.

Other research has focused on surveying senior doctors or 'trainers' about their views on how the EWTD has impacted on medical training. Tsouroufli and Payne ${ }^{23}$ held qualitative interviews with 20 consultants, from surgical and medical specialties, who trained junior doctors across six trusts in Wales in 2005. These trainers considered that there was a disintegration of the apprenticeship style of learning in clinical training following the implementation of the EWTD and the increased use of shift work. Respondents commented on 'the reduced availability of trainees, reduced interaction between trainees and trainers, and reduced continuity' among effects of the implementation of the EWTD. ${ }^{23}$ Doctors also commented on the new roles and increased workload of consultant trainers as a result of MMC. ${ }^{23}$ A GMC survey of trainers $(\mathrm{n}=17000)$ conducted between 2009 and 2010 found that $58 \%$ believed that the training needs of their trainees were being met within the $48 \mathrm{~h}$ work week. However, $74.3 \%$ of trainers from the surgical specialties did not believe their trainees' needs were being met. ${ }^{18}$ The GMC report in 2010 identified particular specialties as having consistent 
concerns related to EWTD's effect on training opportunities, namely surgical specialties, obstetrics and gynaecology, emergency medicine, anaesthetics and paediatrics. ${ }^{18}$ The GMC survey found that $49 \%$ of trainers indicated that they have changed the way they teach trainees as a result of EWTD. ${ }^{18}$ Just as junior doctors must adapt their learning strategy within limited working hours, a culture shift from senior doctors might be necessary to meet the evolving demands of medical training.

A systematic review of the literature reported inconclusive findings on the effects of EWTD. ${ }^{24}$ In fact, it is challenging to differentiate the changes resulting from EWTD in isolation from those that may have resulted from other changes, including Modernising Medical Careers, The New Deal or wider structural reforms to the NHS. ${ }^{25}$ Importantly, it is difficult to differentiate between the effects of EWTD itself and the ways that Trusts and Deaneries have implemented it. ${ }^{4}$ For example, a GMC analysis of Annual Deanery Reports from 2009 found that a few deaneries reported gaps in rotas which they felt were due to EWTD. However, others reported compliance (though whether their juniors would invariably agree may be open to question) and successful implementation of EWTD. ${ }^{18}$

\section{Strengths and limitations}

This study is based on large numbers of respondents from across the UK. It covers doctors who graduated from all UK medical schools in 2 years, 1999 and 2000. It is a systematic survey of all who were willing to respond in cohorts that have extensive experience of work before and after the full implementation of the EWTD in medical practice. As with all surveys, nonresponder bias is possible. We included the section about the EWTD in a multipurpose survey with several other sections. We did not deem it possible to delve in detail into the doctors' views about the EWTD: in our core work, we try to be thrifty with questions to encourage doctors to respond.

The study represents the subjective views of doctors in these cohorts and does not include any objective impact of the EWTD on the NHS, junior or senior doctors. Some caution is advised in interpreting the results as respondents may have had difficulty in separating the effects of EWTD itself, and the way it has been implemented, from those of other reforms to the NHS and medical training. In addition, we did not have information on various factors that may have influenced the findings, such as hospital size or the nature of rotations and the organisation of shift work. For example, it has been suggested that surgical trainees working in large hospitals, with larger volumes of operations, might be less dissatisfied with the EWTD since these trainees have not been so limited in their operating experience. ${ }^{26}$ A further limitation is that our questioning, necessarily brief for practical reasons, aimed to seek views on benefit; for those who disagreed that the EWTD had shown benefit, particularly in respect of senior doctors, we do not know whether they thought that the effect of EWTD had been damaging or simply neutral. It is striking, nonetheless, that only such a small proportion felt able to specify that the EWTD had positive benefit.

\section{CONCLUSION}

The majority of doctors graduating from medical school in 1999 and 2000 did not agree that the EWTD, as implemented in their experience, had benefited the NHS or senior doctors. They were less negative about the impact of EWTD on junior doctors. We do not recommend, and nor did our respondents advocate, a return to the very long working hours of earlier times. However, there is a need for organisational changes, including well-coordinated and planned rotas, with consideration of points made by doctors in the accompanying paper, ${ }^{5}$ to improve opportunities for training and clinical experience while maintaining the requirement and the benefit of EWTD-compliant hours.

Acknowledgements The authors would like to thank Emma Ayres for administering the surveys and Janet Justice and Alison Stockford for data entry. They are grateful to all the doctors who participated in the surveys.

Contributors MJG and TWL designed the study. JJM and TWL undertook the analysis and JJM wrote the first draft. All authors contributed to further drafts and all agreed the final manuscript.

Funding This is an independent report commissioned and funded by the Policy Research Programme in the Department of Health (grant reference 016/0116). The views expressed are not necessarily those of the funding body.

\section{Competing interests None.}

Ethics approval This study was approved by the National Research Ethics Service, following referral to the Brighton and Mid-Sussex Research Ethics Committee in its role as a multicentre research ethics committee (ref 04/ Q1907/48).

Provenance and peer review Not commissioned; externally peer reviewed.

Data sharing statement The authors may be able to provide aggregated data on which the analysis is based, on request.

Open Access This is an Open Access article distributed in accordance with the Creative Commons Attribution Non Commercial (CC BY-NC 3.0) license, which permits others to distribute, remix, adapt, build upon this work noncommercially, and license their derivative works on different terms, provided the original work is properly cited and the use is non-commercial. See: http:// creativecommons.org/licenses/by-nc/3.0/

\section{REFERENCES}

1. NHS Employers. European Working Time Directive. 2011. http:// www.nhsemployers.org/PlanningYourWorkforce/MedicalWorkforce/ EWTD/Pages/EWTD.aspx (accessed 3 Sep 2013).

2. Royal College of Physicians. The European Working Time Directive and working hours. http://www.rcplondon.ac.uk/policy/physician -development/ewtd (accessed 3 Sep 2013).

3. Royal College of Surgeons. Surgeons, the European working time directive and August 1st 2009. 2009. http://www.rcseng.ac.uk/news/ surgeons-the-european-working-time-directive-and-august-1st2009\#.Ud51DG0U3Zg (accessed 3 Sep 2013).

4. Temple J. NHS: Medical Education England, London Time for training. A review of the impact of the European Working Time Directive on the quality of training. 2010. http://www.mee.nhs.uk/ PDF/14274\%20Bookmark\%20Web\%20Version.pdf (accessed 3 Sep 2013). 
5. Clarke RT, Pitcher A, Lambert TW, et al. Doctors' views on the implementation of the European Working Time Directive: a qualitative analysis. BMJ Open 2014;4:e004390. doi:10.1136/bmjopen-2013004390.

6. Goldacre MJ, Turner G, Lambert TW. Variation by medical school in career choices of UK graduates of 1999 and 2000. Med Educ 2004;38:249-58.

7. Evans J, Lee P, Goldacre MJ, et al. Pre-registration house officers' comments on working in the NHS: a qualitative study of the views of UK medical graduates of 1999. Med Teach 2004;26:250-5.

8. Lambert TW, Goldacre MJ, Edwards C, et al. Career preferences of doctors who qualified in the United Kingdom in 1993 compared with those of doctors qualifying in 1974, 1977, 1980, and 1983. BMJ 1996;313:19-24.

9. Goldacre MJ, Davidson JM, Lambert TW. Career choices at the end of the pre-registration year of doctors who qualified in the United Kingdom in 1996. Med Educ 1999;33:882-9.

10. Morrow G, Burford B, Carter M, et al. The impact of the working time regulations on medical education and training: literature review. Durham University: Centre for Medical Education Research, 2012. http://www.gmc-uk.org/The_Impact_of_the_Working_Time_ Regulations_on_Medical_Education_and_Training_Literature_ Review.pdf_51155615.pdf (accessed 3 Sep 2013).

11. Kelly BD, Curtin PD, Corcoran M. The effects of the European Working Time Directive on surgical training: the basic surgical trainee's perspective. Ir J Med Sci 2011;180:435-7.

12. Tait MJ, Fellows GA, Pushpananthan $S$, et al. Current neurosurgical trainees' perception of the European Working Time Directive and shift work. Br J Neurosurg 2008;22:28-31.

13. West D, Codispoti M, Graham T. The European Working Time Directive and training in cardiothoracic surgery in the United Kingdom: a report of the Specialty Advisory Board in Cardiothoracic Surgery of The Royal College of Surgeons of Edinburgh. Surgeon 2007;5:81-5

14. Lowry J, Cripps J. Results of the online EWTD trainee survey. $\mathrm{Br} R$ Coll Surg Engl 2005;87:86-7.

15. Skipworth RJ, Terrace JD, Fulton LA, et al. Basic surgical training in the era of the European Working Time Directive: what are the problems and solutions? Scott Med J 2008;53:18-21.
16. Parsons BA, Blencowe NS, Hollowood AD, et al. Surgical training: the impact of changes in curriculum and experience. J Surg Educ $2011 ; 68: 44-51$.

17. Jackson GP, Tarpley JL. How long does it take to train a surgeon? BMJ 2009;339:b4260.

18. General Medical Council (GMC). GMC quality assurance of specialty including GP training and the European Working Time Regulations: September to June 2010. 2010. http://www.gmc-uk.org/GMC_ quality assurance of Specialty including GP training and the EWTR_Sept_2009_to_June_2010_35872744.pdf (accessed 3 Sep 2013).

19. Goldacre MJ, Stear S, Lambert TW. Session 3: the pre-registration year: the trainees' experience. Med Educ 1997;31:57-60.

20. Lambert TW, Surman G, Goldacre MJ. Views of UK-trained medical graduates of 1999-2009 about their first postgraduate year of training: national surveys. BMJ Open 2013;3:pii: e002723.

21. Richter A, Kostova P, Baur X, et al. Less work: more burnout? A comparison of working conditions and the risk of burnout by German physicians before and after the implementation of the EU Working Time Directive. Int Arch Occup Environ Health 2014:87:205-15.

22. Hutter MM, Kellogg KC, Ferguson CM, et al. The impact of the 80-hour resident workweek on surgical residents and attending surgeons. Ann Surg 2006;243:864-71.

23. Tsouroufli $\mathrm{M}$, Payne $\mathrm{H}$. Consultant medical trainers, modernising medical careers (MMC) and the European time directive (EWTD): tensions and challenges in a changing medical education context. BMC Med Educ 2008;8:31.

24. Moonesinghe SR, Lowery J, Shahi N, et al. Impact of reduction in working hours for doctors in training on postgraduate medical education and patients' outcomes: systematic review. BMJ 2011;342:d1580.

25. General Medical Council (GMC). The impact of the implementation of the European Working Time Directive (EWTD). 2011. http://www. gmc-uk.org/The_impact_of_the_implementation_of_the_European Working_Time_Directive_EWTD_42536543.pdf (accessed 3 Sep 2013).

26. West $D$. European Working Time Directive implementation and cardiothoracic training: larger centers may optimise training. Eur $J$ Cardio Thorac Surg 2007;31:958. 